\title{
Effects of an 8-Week Yoga-Based Physical Exercise Intervention on Teachers' Burnout
}

\author{
Francesca Latino $(\mathbb{D}$, Stefania Cataldi *(D) and Francesco Fischetti $(\mathbb{D}$ \\ Department of Basic Medical Sciences, Neuroscience, and Sense Organs, University of Bari "Aldo Moro", \\ 70123 Bari, Italy; francesca.latino@uniba.it (F.L.); francesco.fischetti@uniba.it (F.F.) \\ * Correspondence: stefania.cataldi@uniba.it; Tel.:+39-34-9125-8004
}

Citation: Latino, F.; Cataldi, S.

Fischetti, F. Effects of an 8-Week Yoga-Based Physical Exercise Intervention on Teachers' Burnout. Sustainability 2021, 13, 2104. https://doi.org/10.3390/su13042104

Academic Editor:

Emilio Villa-González

Received: 18 December 2020

Accepted: 12 February 2021

Published: 16 February 2021

Publisher's Note: MDPI stays neutral with regard to jurisdictional claims in published maps and institutional affiliations.

Copyright: (c) 2021 by the authors. Licensee MDPI, Basel, Switzerland. This article is an open access article distributed under the terms and conditions of the Creative Commons Attribution (CC BY) license (https:/ / creativecommons.org/licenses/by/ $4.0 /)$.

\begin{abstract}
The purpose of this quasi-experimental study was to investigate the efficacy of an 8-week yoga-based physical exercise program to improve mental and emotional well-being and consequently reduce burnout among teachers. We considered yoga because it is a discipline that enhances body awareness and encourages the contact with nature and the respect for every form of life, with a view to a more sustainable and greener global system. We recruited 40 professional educators (40-47 years), teachers in a public high school who reported perceiving signs of stress and emotional discomfort. We randomly assigned the 40 professional educators to either an experimental yoga practice $(\sim 60 \mathrm{~min}$, twice a week) group $(n=20)$ or a control group $(n=20)$ that received a nonspecific training program ( $60 \mathrm{~min}$, twice a week). At baseline and after training we administered the Maslach Burnout Inventory: Educators Survey (MBI-ES) and the State Mindfulness Scale (SMS) to assess teachers' perceived level of awareness and professional burnout. We found a significant Time $\times$ Group interaction for the MBI-ES and SMS, reflecting a meaningful experimental group improvement $(p<0.001)$. No significant pre-post changes were found in the control group. The results suggest that an 8-week yoga practice could aid teachers to achieve a greater body and emotional awareness and prevent professional burnout.
\end{abstract}

Keywords: mindfulness; sustainable physical activity; workplace stress; physical education; exercise; sustainable lifestyle

\section{Introduction}

Western work life is one of the most important causes of stress, discomfort, and anxiety. Our well-being is conditioned by feeling stressed, anxious, always in a rush, or outmatched [1]. The working environment in Western culture is characterized by speed competition, dissatisfaction, excessive requests, holding more positions at the same time, job insecurity, and short timeframes [2]. It is for this reason that stress in the workplace is considered a real public health issue [3].

Constant stress, disillusion, and emotional discomfort can lead down the road to burnout [4,5]. It is mostly related to the working environment and occurs as a result of a prolonged period of heavy workload in association with high-pressure work situations [6], and it is a cause of a permanent state of emotional, physical, and mental exhaustion. Maslach [7] defines job burnout as the result of three dimensions: exhaustion, cynicism, and a sense of inefficacy. Burnout reduces productivity and decreases energy, leaving people helpless, resentful, and makes them feel like they have nothing more to give [8]. The negative effects of burnout spill over into every area of life, including personal relationships, work, and social life. Because of its many consequences, it is important to stay protected from its damaging effects $[9,10]$.

In the recent decades, teaching has been considered one of the most predisposed professions to the development of mental health disorders (i.e., anxiety, depression, anger) or behavioral symptoms (i.e., absenteeism, lack of commitment) [11], so much so that it has been included among the "helping professions" to keep under control $[12,13]$. 
Burnout is a serious psychological syndrome that can affect both low and high experienced teachers [14]. Teaching is a gratifying yet very challenging profession. It is characterized by long and heavy hours of work that prevent teachers from taking care of their physical and mental well-being [15]. They are often left alone in large classes with a lot of prescription on what they should be teaching, requiring a high standard of efficiency and productivity. In addition, there are situations of temporary employment, conflict between colleagues, and the constant need to update-for which teachers do not receive any significant support [16]. These stressful factors are both emotional and physical; thus, preventive and support actions should proceed in parallel with them [17]. Often, in fact, the necessary action programs are nonspecific treatments that do not consider the sources of stress that are particular to this profession [18]. Moreover, they are not body-mind treatments, such as yoga, which allow the integration of mind and body and the channeling of energy in a positive way [19].

Practicing yoga allows one to regain balance, positivity, and hopefully, to improve job satisfaction and bolster well-being on and off the job [20]. The practice of yoga helps one to escape from stress and decrease the mental burden accompanying difficult situations [21]. It promotes the growth of feelings of self-efficacy and self-control [22], diminishing the perception of the emotional components of stress (i.e., burnout) [23]. Thus, the effect of physical activity on burnout is reflected in positive psychological changes that it allows practitioners to obtain [24].

Yoga is a discipline that enhances and encourages contact with nature and respect for every form of life, with a view to a more sustainable and greener global system [25]. Yoga is an accessible route to mindfulness and could be a crucial tool for ensuring ecological balance [26]. It leads people to discover harmony with nature and other people [27]. Therefore, as yoga does not require particular equipment, it is not harmful to the environment [28]. It is, quite simply, practicing mindfulness, meditation, and connection with one's own body. As yoga is an activity that can be done anywhere at any time, it makes yoga the perfect sustainable activity [29]. All these aspects have social, environmental, and economical repercussions influencing positively the inner growth of individuals [30]. Despite the numerous scientific studies conducted in this area [31-35], burnout syndrome among teachers and its relationship to exercise still show many elements that are worthy objects of investigation [36,37]. Most studies in the past have recognized the importance of tackling the problem of stressful conditions and burnout and have discussed various ways by which yoga can address these issues [38-43]; until today, however, not much has been done to experimentally examine the potentialities of yoga on the teaching profession [44,45]. Thus, the main objective of this paper is to fill this gap.

The objectives of our study were therefore to assess the effects of a yoga exercise program on teachers who reported stress and depressive symptoms because of burnout, and to evaluate their changes in physical, mental, and emotional well-being and state of mindfulness pre- and post-intervention. Moreover, this study aimed to provide important indicators that could help contemporary educational institutions to understand the importance of certain physical practices to support their teachers. In fact, it was hypothesized that teachers who learn and adopt a brief yoga intervention manage to decrease their job burnout better than those practitioners engaged in other activities to enhance their physical and mental growth.

\section{Method}

\subsection{Study Design}

We employed a quasi-experimental study design to investigate the effects of an 8-week yoga training program on teachers' burnout that was mostly due to critical situations at work.

The study was conducted in a high school and consisted of 8 weeks of supervised yoga exercises for the intervention group and a nonspecific training program designed to achieve a general psycho-physical wellness for the control group. The evaluation considered 16 lessons, monitoring the participants at the first and eighth week, respectively. 
Measurements were administered 1 week before training (pretest) and directly after training (posttest).

In order to allow statistically meaningful comparisons between different types of activities, the subjects were classified as participants in activities that shared similar characteristics.

\subsection{Participants}

We recruited 40 professional educators (with a teaching load of $18 \mathrm{~h}$ per week) who reported perceiving signs of stress and emotional discomfort-teachers in a public high school, aged 40-47 years ( 3 males and 37 females, $M$ age $=42.89, S D= \pm 2.0$ ) —to participate in the study.

Participation in the research study was voluntary and all high school teachers from local schools were eligible to participate in this study. Inclusion criteria were the following: participants had to be relatively healthy individuals capable of completing a moderate-intensity aerobic exercise session, current teachers at the high school who reported perceiving signs of stress and emotional discomfort, neither current nor past yoga practitioners, and able to abstain from all physical activity outside the parameters of the study protocol during test days. From the study were excluded any teachers with orthopedic conditions limiting their ability to perform exercises, past or current yoga practitioners, and those unable to abstain from all physical activity outside the confines of the study protocol on the testing days.

Fifty-four subjects fulfilled the inclusion criteria and were invited to participate. Of those recruited, 40 agreed to be in the research study and completed the baseline survey, while 14 of those declined to participate because they thought either too great commitment was involved or due to other personal reasons. Consequently, the final sample consisted of 40 participants, 37 of which were female and 3 of which were male, who completed the assessments at baseline and post intervention. The attendees were sent an e-mail containing information about the study 2 weeks before the start of the program. The participants were from the same socioeconomic background and educational level and had similar lifestyle conditions as regards the specific organization of daily life that characterizes those who practice this profession.

We matched participants randomly to one of two treatment conditions. The first group (experimental group; EG; $n=20$ ) was composed of 2 male and 18 female teachers, while the second one (control group; CG; $n=20$ ) was composed of 1 male and 19 female teachers.

The researchers ensured the anonymity of the participants. All subjects gave their informed consent for inclusion before they participated in the study. The study was conducted from October 2019 to November 2019, in accordance with the Declaration of Helsinki. The Department of Basic Medical Sciences, Neurosciences, and Sensory OrgansSports Science Section - at the University of Bari "Aldo Moro" did not consider approval of the Ethics Committee necessary for this study because the research did not provide any clinical, health, or biological treatments.

\section{Procedures}

We administered the intervention program at a local public school at the end of the daily school lessons. The training sessions were scheduled early in the afternoon on Tuesdays and Fridays, specifically from 3 p.m. to 4 p.m., which was the participants' time of preference because they reported that their energy levels were highest in the early afternoon.

Both groups attended twice per week and received $60 \mathrm{~min}$ of supervised group training each day. The yoga intervention was held in a large school conference hall, while the exercise intervention for the control group was given in the gym of the same school, under carefully monitored and controlled conditions.

Before the first training session, a meeting took place, where the content of the exercise training was explained, and the motivation of every single person was verified. Concerning the intervention yoga program, each session included 5 min of breathing exercises, then 
participants were led through $10 \mathrm{~min}$ of a gentle warm-up sequence, followed by $40 \mathrm{~min}$ performance of the main exercises, and lastly, they were guided through 5 min of cooldown sequence and deep relaxation. Specifically, the warm-up consisted of aerobic exercise with a progressive level of difficulty, while the main exercises were designed for flexibility and emphasized yoga's physical and mental benefits; whereas the program of nonspecific exercise involved $10 \mathrm{~min}$ of warm-up sequences, $40 \mathrm{~min}$ of main exercise, and $10 \mathrm{~min}$ of cool-down exercises.

At least six days prior to the intervention, participants were led to the school to undertake two questionnaires regarding measures of psychological functioning: the State Mindfulness Scale (SMS) and the Maslach Burnout Inventory: Educators Survey (MBI-ES). The State Mindfulness Scale and the MBI-ES were administered to investigate the participants' perceived level of awareness, attention, and three dimensions of burnout syndrome, respectively.

The participants completed the psychological functioning questionnaires immediately prior to and following the intervention, in order to allow pre- and posttest data comparison and to evaluate the effects of the intervention program. Both administrations of the State mindfulness Scale and Maslach Burnout Inventory occurred in the same room as the yoga intervention. Initial and final examinations were administered at the same time of the day and under the same experimental conditions.

Because of the sensitive nature of these questionnaires, the respondents were put at ease to enable them to best express their true feelings. The teachers were divided into two groups, and testing took $30 \mathrm{~min}$ for each participant. They were tested individually, and each task and item were explained before the participants started.

To minimize the reactive effect about burnout personal beliefs, the respondents were not aware that the MBI-ES was a burnout measure, and they were not sensitized to the general issue of burnout. The scale was presented as a survey of job-related attitudes and was not linked to burnout in any way [46].

The participants wore clothing appropriate to physical activity and sport shoes throughout the intervention program. The yoga program was performed by an experienced yoga instructor (certified by the Higher Institute for Teacher Training of Yoga of the Italian Federation of Yoga), and all measurements for testing were instructed and supervised by a school physical education teacher. The nonspecific training program was performed by a school physical education teacher, certified by Italian ministry of Education. All trials were performed using a standardized test protocol, observing the same conditions.

\subsection{Measures}

\subsubsection{Maslach Burnout Inventory: Educators Survey (MBI-ES)}

We conducted a psychological functioning assessment with the Maslach Burnout Inventory: Educators Survey (MBI-ES), a well-validated and reliable questionnaire assessing professional burnout.

The MBI-ES is a version of the original Maslach Burnout Inventory that is used for teachers, administrators, and other staff members, and it represents the gold standard for measuring burnout in the education system [47].

The MBI-ES is a 22-item questionnaire using a 7-point Likert-type scale. It measures burnout across 3 factors:

- Emotional Exhaustion (EE; 9 items) refers to the level of feeling emotionally worn-out and drained due to work.

- Depersonalization (DW; 5 items) refers to feeling disconnected or detached from one's own students.

- Personal Accomplishment (PA; 8 items) refers to feelings of expertise and satisfaction in the workplace.

The burnout feelings assessment required responses ranging from 0 , "never", to 6 , "every day". It took about 10 to $15 \mathrm{~min}$ to fill out, and it was self-administered. The scoring 
system formulae used to calculate the score was the standardized Italian version by Sirigatti and Stefanile (1993) [48].

\subsubsection{State Mindfulness Scale (SMS)}

Moreover, we administered the State Mindfulness Scale, a validated measure of state mindfulness, to investigate the participants' perceived level of consciousness and focus of their current experience during a designated time (in our case, we considered the 8 weeks of the intervention) and context (in our case, mindfulness following yoga practice and meditation) [49].

The measure refers to 21 items, which are divided into two subscales: 6 items referring to mindfulness of body sensations and 15 items to mindfulness of mental events. The response scale is of the 5-point Likert-type, ranging from 1, "not at all", to 5, "very well", on the degree to which the statements describe the respondent's experience.

If a respondent's state of mindfulness increased, this suggested they were experiencing a pleasant and greater awareness of their body and mind. The test lasted from 10 to $15 \mathrm{~min}$, including instructions and a practice phase. Evaluation questionnaires were given before and after the intervention to control any state of mindfulness changes.

\subsubsection{Exercise Training Intervention}

During the first two lessons, participants in the yoga intervention gained consciousness of their body postural alignment and of their breathing through the acquisition of proper deep breathing techniques. In the following sessions and for the duration of the intervention, the first part of the session was dedicated to breathing exercises and meditation. They were a huge part of yoga practice because they could bring the mind and the body to a pleasant state by enhancing and regulating the yoga poses.

Later, warm-up sequences consisted of a few basic poses that helped participants to prepare themselves to face the main exercise program (to get ready for the session ahead). It allowed participants not only to prepare the body but also to project the mind into yoga mentality, obtaining a positive detachment from the remainder of the day. Warm-up included pelvic tilts, leg stretches, neck bending, trunk twisting, eagle arms, easy twists, cat-cow stretches, shoulder rotations, downward dog pose, child's pose, and goddess pose.

The main yoga exercises (Tables 1 and A1) were based on the Hatha yoga style. They involved gentle movements and postures designed for people who need to restore themselves physically and mentally. This made the program easily accessible to everyone, without having to worry about their physical limitations [50]. It was based on aerobic exercises and poses that were easily executable and accessible to every participant, were low-risk regarding injuries, involved all the muscle groups in the body, and improved cardiorespiratory condition [51]. The objective was to bring stress relief and relaxation. The protocol included:

1. Hatha yoga aerobic exercises

2. Hatha yoga postures

3. Meditation and Awareness

During all exercises, participants were encouraged to focus their attention on the perception of their feelings and body to grasp what occurred physiologically and emotionally. Within each workout session, rest periods were $60 \mathrm{~s}$ between exercises and two minutes between sets during weeks one and two. As for the remaining weeks, rest periods were dropped down to $30 \mathrm{~s}$ and $1 \mathrm{~min}$. The progression of the training was designed to be performed in two consecutive sets for each of the exercises before moving to the next exercise. 
Table 1. Yoga plan for experimental group (EG): main exercises.

Week
Complete 2 sets of 12 repetitions for all exercises
At the beginning of all sessions-BREATH AND RELAXATION: Easy pose
(sukhasana); bumble bee breath (bhramari pranayama); viloma pranayama; instant
relaxation technique (IRT); sun salutation breath (surya namaskar).
At the end of all sessions-BREATH AND RELAXATION: Circle of joy breath;
alternate nostril breathing (nadi shodhana); skull shining breathing technique
(kapalabhati pranayama); corpse pose (savasana); deep relaxation technique (DRT).
Standing wide legged pose hands on hips (prasarita tadasana); revolved wide
legged forward bend pose (parivrtta prasarita padottanasana); revolved
head-to-knee pose (parivrtta janu sirsasana); locust pose torso on floor one leg up
(ardha salabhasana); cobra pose (bhujangasana); cradle pose straight leg
(hindolasana); half upright seated angle pose (ardha urdhva upavistha konasana);
crocodile pose (makarasana).
Chair Pose (Utkatasana); garland pose (malasana); one legged bow pose
preparation (eka pada dhanurasana preparation); locust pose variation (salabhasana
variation); revolved cobra pose (parivrtta bhujangasana); locust pose variation
(salabhasana variation); half lord of the fishes pose (ardha matsyendrasana); half
lord of the fishes pose variation hand up (ardha matsyendrasana).

Garland pose (malasana); boat pose (navasana); half plough pose (ardha halasana);
seated forward bend pose (paschimottanasana); four limbed staff pose (chaturanga
dandasana); snake pose (sarpasana); dolphin pose (catur svanasana); dolphin plank
variation one leg raised (catur svanasana phalakasana variation one leg raised).

Each training session ended with a brief full-body cool-down exercise, deep relaxation, and breathing. It consisted of a sequence of static stretching exercises which included warrior pose, side angle variation, low lunge, calf stretch, downward dog, toe touch stretch, quadriceps stretch, standing full-body stretch, downward dog, modified pigeon, leg pull, cobra stretch, and child's pose. 
The control group started each training session with a brief full body dynamic warmup, continued with a sequence of main exercises designed to improve general physical wellness, and ended with cool-down exercises.

Warm-up included marching in place, wide toe touch, leg swings, arm swings, shoulder rotations, hip rotations, push-ups, lunges, walking jacks, jumping jacks, hip circles, and bodyweight squats. Regarding main exercises, they followed the protocol described below (Tables 2 and A2):

- bodyweight exercises

- group exercises with small training gear

- joint mobility exercises

- calisthenics basic workout

- Pilates exercises

Table 2. Intervention plan for control group (CG): main exercises.

\begin{tabular}{|c|c|}
\hline Week & Exercise \\
\hline 1 & $\begin{array}{l}\text { Complete } 2 \text { sets of } 10 \text { repetitions for all exercises: Standing march in place, standing } \\
\text { side kick, arm circles, half roll-down, lower lift, leg circle, simple side bends, up-down } \\
\text { dogs, wall push-ups, reverse crunches, table top, rocker, cork-screw, swan dive, } \\
\text { side-to-side rolling. }\end{array}$ \\
\hline 2 & $\begin{array}{c}\text { Complete } 2 \text { sets of } 10 \text { repetitions for all exercises: Sit to stands, kneeling hip-ups, } \\
\text { Russian twists, superman, crisscross, neck-pull, spine twist, jack knife, hip twist, } \\
\text { swimming, control balance, grasshopper, Pilates push-ups, alternate arm flexion on } \\
\text { the foam roller, side-lying hip abduction. }\end{array}$ \\
\hline 3 & $\begin{array}{c}\text { Complete } 2 \text { sets of } 12 \text { repetitions for all exercises: Windmills, step jacks, kneeling } \\
\text { inchworms, bridge holds, scissor kick, teaser, side bent, boomerang, seal, crab, roller } \\
\text { dip, saw, stability ball dumbbell press, standing one-arm extension with resistance } \\
\text { band, kneeling dolphin push-ups. }\end{array}$ \\
\hline 4 & $\begin{array}{l}\text { Complete } 2 \text { sets of } 12 \text { repetitions for all exercises: Standing saw, alternating step-up, } \\
\text { stretch arm forward, hip circle, rolling like a ball, kneeling plank, bridge lifts, bicycles, } \\
\text { pendulum, mermaid, upper back roll, seated cable row with resistance band, stability } \\
\text { ball squat, stability ball dumbbell fly, shoulder shrug with resistance bands. }\end{array}$ \\
\hline 5 & $\begin{array}{l}\text { Complete } 2 \text { sets of } 12 \text { repetitions for all exercises: Standing roll-down, chest expansion, } \\
\text { calf raises, kneeling side plank, the hundred, pelvic curl, bridge with arm extension, } \\
\text { leg sweep-left, leg lift and arm extension, hover leg lift, curl ups, lower back curl, } \\
\text { stability ball dumbbell row, seated lat pulldown with resistance band, clams. }\end{array}$ \\
\hline 6 & $\begin{array}{l}\text { Complete } 2 \text { sets of } 15 \text { repetitions for all exercises: March in place high knee, kneeling } \\
\text { slide, open leg balance, roll up, single-leg stretch, single-leg kick, bridge with } \\
\text { alternating outer thigh squeeze, left clam, hamstring roll, assisted squat, straight-leg } \\
\text { donkey kick, floor press, floor dumbbell Russian twist, single-leg biceps cable curl, } \\
\text { stability ball triceps extension. }\end{array}$ \\
\hline 7 & $\begin{array}{l}\text { Complete } 2 \text { sets of } 15 \text { repetitions for all exercise: Sparklers, leg swings, slow motion } \\
\text { mountain climbers, double-leg stretch, double-leg kick, twist and reach, ball rollout, } \\
\text { reverse clam, single leg extension, bird dog in knee hover, lunge and reach, front raise } \\
\text { combo, foam roller tucks, single leg bicycle tap, flyers. }\end{array}$ \\
\hline 8 & $\begin{array}{l}\text { Complete } 2 \text { sets of } 15 \text { repetitions for all exercise: Standing Pilates legwork, Romanian } \\
\text { deadlift, seated hammer curl on stability ball, single leg balance, double leg extension, } \\
\text { rollback and twist, teaser with one leg, leg pull front, quadruped leg lifts, bird dog, } \\
\text { knee hover tap, glutes roll, forward lunges, plank to downward dog, deadbug. }\end{array}$ \\
\hline
\end{tabular}

Within each workout session, rest periods were $60 \mathrm{~s}$ between exercises and two minutes between sets during weeks one and two. As for the remaining weeks, rest periods were dropped down to $30 \mathrm{~s}$ and $1 \mathrm{~min}$. The progression of the training was designed to be performed in two consecutive sets for each exercise before moving to the next exercise. Cool-down consisted of a variety of static stretching exercises, which included glute stretch, 
standing quad stretch, side bench stretch, arm-cross shoulder stretch, overhead triceps stretch, lower back stretch, abdominal stretch, and child's pose. Cool-down was important for muscle relaxation and for the improvement of joint range of motion.

\subsubsection{Statistical Analysis}

We carried out statistical analyses using SAS JMP Statistics (Version $<15.1>$, SASA Institute Inc., Cary, NC, USA, 2020). We present data as group mean (M) values and standard deviations $(S D)$. Normality of all variables was tested using Shapiro-Wilk test procedure and data were checked for assumptions of homogeneity of variances (i.e., Levene test). We used an independent sample $t$-test to evaluate group differences at baseline and a two-way ANOVA (group experimental/control) $\times$ time (pre/post intervention), with repeated measures on the time dimension, conducted to examine the effect of the training on all examined variables. When Group $\times$ Time interactions reached significance, groupspecific post hoc tests, such as paired $t$-tests, were conducted to identify the significant comparisons.

Partial eta squared $\left(\eta^{2} p\right)$ was used to estimate the magnitude of the difference within each group and interpreted using the following criteria: small $\left(\eta^{2} p<0.06\right)$, medium $\left(0.06 \leq \eta^{2} p<0.14\right)$, large $\left(\eta^{2} p \geq 0.14\right)$. Effect sizes (ES) for the pairwise comparisons were determined by Cohen's $d$ and interpreted as small, moderate, and large effects defined as $0.20,0.50,0.80$, respectively [52]. Statistical significance was set at $p \leq 0.05$.

\section{Results}

All participants received the treatment conditions as allocated and their average adherence (attendance) to intervention sessions was $91.4 \%$ (14.6 of 16 actual sessions). No injuries were associated with either of the training programs. The experimental and control groups did not differ significantly at baseline in age, anthropometric characteristics, as well as in psychological measures $(p>0.05)$. Pre- and post-intervention results for all dependent measures are presented in Tables 3 and A3.

Table 3. Changes in emotional well-being and state mindfulness after 8-week of yoga intervention.

\begin{tabular}{|c|c|c|c|c|c|c|}
\hline & \multicolumn{3}{|c|}{ Experimental Group $(n=20)$} & \multicolumn{3}{|c|}{ Control Group $(n=20)$} \\
\hline & Baseline & Posttest & $\Delta$ & Baseline & Posttest & $\Delta$ \\
\hline MBI-ES & & & & & & \\
\hline Emotional Exhaustion & $53.03(5.58)$ & $45.62(6.54) t^{*}$ & $-7.41(5.95)$ & $50.79(5.86)$ & $51.81(5.72)$ & $1.02(2.75)$ \\
\hline Depersonalization & $28.85(3.65)$ & $23.23(4.09) t^{*}$ & $-5.62(3.89)$ & $28.74(3.12)$ & $28.12(3.16)$ & $-0.62(2.51)$ \\
\hline $\begin{array}{c}\text { Personal Accomplishment } \\
\text { SMS }\end{array}$ & $7.26(2.95)$ & $12.32(4.29) t^{*}$ & $5.06(3.39)$ & $4.84(3.75)$ & $5.05(4.04)$ & $0.21(2.88)$ \\
\hline $\begin{array}{l}\text { State mindfulness of bodily } \\
\text { sensations }\end{array}$ & $5.55(2.30)$ & $14.45(2.11) t^{*}$ & $8.9(2.71)$ & $6.45(1.95)$ & $7.8(2.30)$ & $1.35(1.89)$ \\
\hline $\begin{array}{l}\text { State mindfulness of mental } \\
\text { events }\end{array}$ & $15.8(2.62)$ & $30.9(4.73) t^{*}$ & $15.1(5.40)$ & $16.45(2.78)$ & $19.1(5.28)$ & $2.65(4.80)$ \\
\hline
\end{tabular}

Note: values are presented as mean $( \pm \mathrm{SD}) ; \Delta$ : pre- to post-training changes; + Significant 'Group $\times$ Time' interaction: significant effect of the intervention $(p<0.001)$; MBI-ES: Maslach Burnout Inventory_Educators Survey; SMS: State mindfulness Scale. * Significantly different from pretest $(p<0.001)$.

\subsection{Maslach Burnout Inventory: Educators Survey}

A two-factor repeated measures ANOVA found a significant Time $\times$ Group interaction for all three burnout factors: Emotional Exhaustion $\left(F_{1,38}=33.09, p<0.001, \eta^{2} p=0.46\right.$, large effect size), Depersonalization $\left(F_{1,38}=23.24, p<0.001, \eta^{2} p=0.38\right.$, large effect size $)$, and Personal Accomplishment $\left(F_{1,38}=23.72, p<0.001, \eta^{2} p=0.38\right.$, large effect size).

Post hoc analysis revealed that the experimental group had a significant decrease from pre- to posttest in Emotional Exhaustion $(t=-5.57, p<0.001, d=1.24$, large effect size) and in Depersonalization $(t=-6.45, p<0.001, d=1.44$, large effect size) scores. In the same way, the experimental group showed a significant increase in Personal Accomplishment 
score $(t=6.67, p<0.001, d=1.49$, large effect size). No correction was applied to the post hoc paired $t$-test. No significant changes were found for the control group $(p>0.05)$.

\subsection{State Mindfulness Scale (SMS)}

A significant Time $\times$ Group interaction was also found for SMS state mindfulness of bodily sensations $\left(F_{1,38}=59.23, p<0.001, \eta^{2} p=0.60\right.$, large effect size $)$ and SMS state mindfulness of mental events $\left(F_{1,38}=103.96, p<0.001, \eta^{2} p=0.73\right.$, large effect size). Moreover, post hoc analysis revealed that the experimental group made significant improvements in both state mindfulness of bodily sensations $(t=14.67, p<0.001, d=3.28$, large effect size) and state mindfulness of mental events $(t=12.48, p<0.001, d=2.79$, large effect size). No correction was applied to the post hoc paired $t$-test. No significant changes were found for the control group $(p>0.05)$.

\section{Discussion}

The aim of this research was to investigate the relationship between an 8-week yoga intervention and professional burnout.

In this study, the results reveal that the 8-week of yoga exercise intervention program significantly helped teachers attain a greater awareness of their emotions and body sensations and improved professional burnout symptoms. This supported the initial hypothesis that the meditative character of the exercises was responsible for the significant difference between the two groups. Indeed, the results revealed that schoolteachers would benefit from incorporating similarly structured courses into their working life.

The first important finding of the present study concerned the positive impact that the yoga training program had on the state of physical fatigue. This was confirmed by the fact that the group who practiced Hatha yoga exercise showed improvement of selfcare, which is developed through the practice of meditation. In fact, yoga meditation was a kind of self-awareness practice, helping individuals to understand themselves more deeply [53]. Becoming aware provides them the possibility to deal with critical situations in an appropriate manner, changing old behaviors [54].

Perhaps the most striking finding of the present study was the evidence of the efficacy of yoga to reduce burnout symptoms among teachers practicing at a public school. Compared to the control group, the group treated with yoga showed a lower state of mental fatigue, emotional exhaustion, and depersonalization at the end of 8 weeks of treatment. In addition, they showed significant enhancements in the perception of feelings, such as self-reliance, mental clarity, self-possession, excitement, and energy. These factors were the result of a higher self-introspection, self-knowledge, and self-care by the experimental group. Indeed, mind-body practices such as Hatha yoga were techniques of fundamental importance in the administration of distress and resilience-building [55].

Lastly, another important finding that positively connected the yoga practice that teachers participated in with stress reduction was evidence of their increased sense of personal accomplishment and career satisfaction. These results stemmed from the advantages of yoga exercises and meditation. They gave the teachers an important support in reaching an optimal and complete wellness of body and mind that can enhance them in their jobs.

These findings were in line with previous studies confirming the existence of a positive link between yoga practice and the prevention of workplace stress [56,57].

Several research studies [58-64] that have focused on the benefits of exercise in decreasing the effects of stress have documented this positive relationship. Many researchers have noted that yoga too provides numerous advantages. Exercise, in particular yoga, is an important topic of study, and its practicing is strongly recommended in order to combat stressors, to the extent that a significant number of studies have demonstrated its potential effects on psycho-physical wellness [65].

According to de Bruin et al. [43], a group training mindfulness meditation program enhanced functional status and well-being, reducing physical symptoms and psychological distress. The authors also concluded that this intervention may have long-term beneficial 
effects. Yoga's meditative character and relaxing power are excellent ways to prevent and solve stressors and reinvigorate the mind. In particular, those forms of meditation and enhancing mindfulness are extremely effective in diminishing negative emotions related to burnout. They help in balancing mind and body and in increasing self-efficacy. In the same way, Michalsen et al. [66] concluded that yoga practice was able to diminish depression and anxiety. In this respect, Reibel, Greeson, Brainard, and Rosenzweig [67] suggested higher levels of training in building resilience to emotional stress for teaching professionals. Furthermore, practicing yoga is a convenient and practical way to relieve tension from stresses on the job and to educate teaching staff to improve posture, energy, and attention span, and to develop feelings of overall wellness [68,69]. Consequently, it was possible to report that the findings of the previous studies corroborate our idea, whereby teachers had meaningfully enhanced well-being and resilience to stress following the yoga intervention. Despite the contribution regarding the significant relationship between stress, burnout symptoms, yoga, and meditation, some limitations were present within this study. The first is related to the small sample size $(n=40)$, which included very few men, due to the obstacle in finding teachers who wanted to participate. Moreover, the sample was recruited from a population of teachers at local public schools located in a small district. Consequently, the results might not be representative of other teachers with different demographic characteristics. A second limitation regards the lack of an effect size assessment for the pretest group differences. Another limitation was the use of a self-selected sample; thus, it could be supposed that participants were strongly interested in participating in yoga sessions. Therefore, their hopes to reach an overall emotional wellness may have influenced the final results. A last limitation concerns the lack of a long-term assessment on stressors and resilience response. Future research would need to examine these possibilities in order to explain these variables. However, the results obtained could provide important indications for future studies. In fact, the strengths of this study represent proof that this simple and effective approach brought health protection to teaching staff.

School training programs for teachers often give voice to the importance of self-care during the working period. However, few programs specifically address this outside of theoretical knowledge. To address this perceived need, firstly, headmasters should be persuaded of the usefulness of this mind-body practice: they should have confidence in the positive effects it produces. When they are convinced of the usefulness of this practice, it could become a training accompanying teachers' working lives. Secondly, within schools the yoga philosophy should become an integral part of its workers' lifestyle, established by school policy.

Thus, educational institutions must acknowledge the importance of this beneficent approach, recognizing that yoga may be a concrete strategy for health promotion among teachers.

\section{Conclusions}

From the present research work, it could be deduced there was a positive correlation between stressors and yoga practice. Our findings demonstrated how even a brief program of yoga was able to improve psycho-physical well-being and a resilience response on the job. Thus, considering the significant and positive benefits and the absence of any risk of a gentle yoga program, we think school organizations should offer yoga sessions to their teachers.

This work represents just a first step to determine the efficacy of a yoga intervention to regenerate body and mind by lowering burnout among teachers. Considering the effect size shown, this yoga treatment is very hopeful and should be used as a starting point for future verifications, but further research will be necessary to confirm, compare, and extend current knowledge. Enhancing yoga's positive effect in optimizing self-care and decreasing burnout, the yoga program discussed in this study was organized to include gentle meditation exercises that did not need a particular setting and could even 
be adaptable to the working environment. However, we suggest it would be preferable to arrange the more challenging sessions of the exercises using an individualized approach, which could provide a significant effect in relation to the teachers' special needs.

Future studies should be directed toward determining a dose-response effect for yoga practice in relationship to job stressors. Moreover, it would be interesting to evaluate the effectiveness of any long-term effects of yoga as far as burnout, resilience, and self-care response among professional educators. Only then could we finally prescribe a detailed and personalized yoga-based treatment in order to improve burnout symptoms.

Author Contributions: F.L. designed the study, conducted the research, carried out the statistical analysis, was involved in the interpretation of data, and wrote and revised the manuscript. S.C. collected data, was involved in the interpretation of data, and revised the manuscript. F.F. coordinated the study, interpreted the data, and revised the manuscript. All authors contributed intellectually to the manuscript, and all authors have read the manuscript and approved the submission. All authors have read and agreed to the published version of the manuscript.

Funding: This research received no external funding.

Institutional Review Board Statement: The study was conducted from October 2019 to November 2019, in accordance with the guidelines of the Declaration of Helsinki. For this study, the Department of Basic Medical Sciences, Neurosciences and Sensory Organs-Sports Science Section-at the University of Bari "Aldo Moro", did not consider the approval of the Ethics Committee necessary because the research did not provide any clinical, health, or biological treatments.

Informed Consent Statement: Informed consent was obtained from all subjects involved in the study.

Data Availability Statement: The data presented in this study are available on request from the corresponding author. The data are not publicly available due to privacy restrictions.

Conflicts of Interest: The authors declared no potential conflicts of interest.

\section{Appendix A}

Table A1. Yoga plan for EG: main exercises.

Week
Complete 2 sets of 12 repetitions for all exercises
At the beginning of all sessions-BREATH AND RELAXATION: Easy pose
(sukhasana); bumble bee breath (bhramari pranayama); viloma pranayama; instant
relaxation technique (IRT); sun salutation breath (surya namaskar).
At the end of all sessions-BREATH AND RELAXATION: Circle of joy breath;
alternate nostril breathing (nadi shodhana); skull shining breathing technique
(kapalabhati pranayama); corpse pose (savasana); deep relaxation technique (DRT).


Table A1. Cont.

\begin{tabular}{|c|c|}
\hline Week & Exercise \\
\hline 4 & $\begin{array}{c}\text { Garland pose (malasana); boat pose (navasana); half plough pose (ardha halasana); } \\
\text { seated forward bend pose (paschimottanasana); four limbed staff pose (chaturanga } \\
\text { dandasana); snake pose (sarpasana); dolphin pose (catur svanasana); dolphin plank } \\
\text { variation one leg raised (catur svanasana phalakasana variation one leg raised). }\end{array}$ \\
\hline 5 & $\begin{array}{l}\text { Standing forward fold pose (uttanasana); mountain pose namaste (pranamasana); } \\
\text { raised arms pose (hasta uttanasana); downward facing dog pose (adho mukha } \\
\text { svanasana); four limbed staff pose variation high (caturanga dandasana variation } \\
\text { high); three legged downward facing dog pose (tri pada adho mukha svanasana); } \\
\text { side plank pose (vasisthasana); downward facing hero pose (adhomukha virasana). }\end{array}$ \\
\hline 6 & $\begin{array}{l}\text { Revolved chair pose (parivrtta utkatasana); noose pose (pasasana); crescent low lunge } \\
\text { pose variation knee on floor (ashwa sanchalanasana); eight limbed pose } \\
\text { (ashtangasana); tiger pose variation (vyaghrasana variation); cycling pose (pada } \\
\text { sanchalanasana); fish pose (matsyasana); bridge pose (setubandha sarvangasana). }\end{array}$ \\
\hline 7 & $\begin{array}{l}\text { Airplane pose (dekasana); bowing yoga mudra (balasana bowing yoga mudra); cat } \\
\text { pose variation knee (marjaryasana variation knee); camel pose (ustrasana); heron pose } \\
\text { (krounchasana); superman pose (vimanasana variation arms forward); wind release } \\
\text { pose nose to knee (pawanmuktasana nose to knee); revolved head-to-knee pose } \\
\text { (parivrtta janu sirsasana). }\end{array}$ \\
\hline 8 & $\begin{array}{l}\text { Sugarcane pose (ardha chandra chapasana); standing hand to big toe pose (utthita } \\
\text { hasta padangusthasana); half moon pose (ardha chandrasana); rabbit pose } \\
\text { (sasangasana); shoulderstand pose (sarvangasana); plough pose (halasana); balancing } \\
\text { prana pose (samanasana); revolved abdomen twist pose (jathara parivartanasana). }\end{array}$ \\
\hline
\end{tabular}

Table A2. Intervention plan for CG: main exercises.

Week
Complete 2 sets of 10 repetitions for all exercises: Standing march in place, standing
side kick, arm circles, half roll-down, lower lift, leg circle, simple side bends, up-down
dogs, wall push-ups, reverse crunches, table top, rocker, cork-screw, swan dive,
side-to-side rolling.


Table A2. Cont.

\begin{tabular}{cc}
\hline Week & Exercise \\
\hline 7 & $\begin{array}{c}\text { Complete 2 sets of 15 repetitions for all exercises: Sparklers, leg swings, slow motion } \\
\text { mountain climbers, double-leg stretch, double-leg kick, twist and reach, ball rollout, } \\
\text { reverse clam, single leg extension, bird dog in knee hover, lunge and reach, front raise } \\
\text { combo, foam roller tucks, single leg bicycle tap, flyers. }\end{array}$ \\
& $\begin{array}{c}\text { Complete 2 sets of 15 repetitions for all exercises: Standing Pilates legwork, Romanian } \\
\text { deadlift, seated hammer curl on stability ball, single leg balance, double leg extension, } \\
\text { rollback and twist, teaser with one leg, leg pull front, quadruped leg lifts, bird dog, } \\
\text { knee hover tap, glutes roll, forward lunges, plank to downward dog, deadbug. }\end{array}$ \\
\hline
\end{tabular}

Table A3. Changes in emotional well-being and state mindfulness after 8-weeks of yoga intervention.

\begin{tabular}{ccccccc}
\hline & \multicolumn{2}{c}{ Experimental Group $(n=20)$} & \multicolumn{3}{c}{ Control Group $(n=20)$} \\
\hline & Baseline & Posttest & $\Delta$ & Baseline & Posttest & $\Delta$ \\
\hline MBI-ES & & & & & & \\
Emotional Exhaustion & 53.03 & $45.62(6.54)$ & -7.41 & 50.79 & 51.81 & 1.02 \\
& $(5.58)$ & $\dagger^{*}$ & $(5.95)$ & $(5.86)$ & $(5.72)$ & $(2.75)$ \\
Depersonalization & 28.85 & $23.23(4.09)$ & -5.62 & 28.74 & 28.12 & -0.62 \\
Personal & $(3.65)$ & $\dagger^{*}$ & $(3.89)$ & $(3.12)$ & $(3.16)$ & $(2.51)$ \\
Accomplishment & 7.26 & $12.32(4.29)$ & 5.06 & 4.84 & 5.05 & 0.21 \\
SMS & $(2.95)$ & $\dagger^{*}$ & $(3.39)$ & $(3.75)$ & $(4.04)$ & $(2.88)$ \\
State mindfulness of & 5.55 & $14.45(2.11)$ & 8.9 & 6.45 & 7.8 & 1.35 \\
bodily sensations & $(2.30)$ & $\dagger^{*}$ & $(2.71)$ & $(1.95)$ & $(2.30)$ & $(1.89)$ \\
State mindfulness of & 15.8 & $30.9(4.73)$ & 15.1 & 16.45 & 19.1 & 2.65 \\
mental events & $(2.62)$ & $\dagger^{*}$ & $(5.40)$ & $(2.78)$ & $(5.28)$ & $(4.80)$ \\
\hline
\end{tabular}

Note: values are presented as mean $( \pm \mathrm{SD}) ; \Delta$ : pre- to post-training changes; † Significant Group $\times$ Time interaction: significant effect of the intervention $(p<0.001)$. ${ }^{*}$ Significantly different from pre-test $(p<0.001)$.

\section{References}

1. Grensman, A.; Acharya, B.D.; Wändell, P.; Nilsson, G.H.; Falkenberg, T.; Sundin, O.; Werner, S. Effect of traditional yoga, mindfulness-based cognitive therapy, and cognitive behavioral therapy, on health related quality of life: A randomized controlled trial on patients on sick leave because of burnout. BMC Complement. Altern. Med. 2018, 18, 80. [CrossRef] [PubMed]

2. Stansfeld, S.; Candy, B. Psychosocial work environment and mental health-A meta-analytic review. Scand. J. Work Environ. Health 2006, 32, 443-462. [CrossRef]

3. Aikens, K.A.; Astin, J.; Pelletier, K.R.; Levanovich, K.; Baase, C.M.; Park, Y.Y.; Bodnar, C.M. Mindfulness goes to work: Impact of an online workplace intervention. J. Occup. Environ. Med. 2014, 56, 721-731. [CrossRef]

4. Roeser, R.W.; Schonert-Reichl, K.A.; Jha, A.; Cullen, M.; Wallace, L.; Wilensky, R.; Oberle, E.; Thomson, K.; Taylor, C.; Harrison, J. Mindfulness training and reductions in teacher stress and burnout: Results from two randomized, waitlist-control field trials. J. Educ. Psychol. 2013, 105, 787-804. [CrossRef]

5. Yu, X.; Wang, P.; Zhai, X.; Dai, H.; Yang, Q. The effect of work stress on job burnout among teachers: The mediating role of self-efficacy. Soc. Indic. Res. 2015, 122, 701-708. [CrossRef]

6. Naczenski, L.M.; Vries, J.D.; de van Hooff, M.L.M.; Kompier, M.A.J. Systematic review of the association between physical activity and burnout. J. Occup. Health 2017, 59, 477-494. [CrossRef]

7. Maslach, C. Job Burnout: New Directions in Research and Intervention. Curr. Dir. Psychol. Sci. 2003, 12, 189-192. [CrossRef]

8. Awa, W.L.; Plaumann, M.; Walter, U. Burnout prevention: A review of intervention programs. Patient Educ. Couns. 2010, 78, 184-190. [CrossRef] [PubMed]

9. Capone, V.; Joshanloo, M.; Park, M.S. Burnout, depression, efficacy beliefs, and work-related variables among school teachers. Int. J. Educ. Res. 2019, 95, 97-108. [CrossRef]

10. Flook, L.; Goldberg, S.B.; Pinger, L.; Bonus, K.; Davidson, R.J. Mindfulness for teachers: A pilot study to assess effects on stress, burnout and teaching efficacy. Mind. Brain Educ. 2013, 7, 182-195. [CrossRef] [PubMed]

11. Pulido-Martos, M.; Lopez-Zafra, E.; Estévez-López, F.; Augusto-Landa, J.M. The Moderator Role of Perceived Emotional Intelligence in the Relationship between Sources of Stress and Mental Health in Teachers. Span. J. Psychol. 2016, 19, E7. [CrossRef] [PubMed]

12. Esteras, J.; Chorot, P.; Sandín, B. Sintomatología física y mental asociada al síndrome de burnout en los profesionales de la enseñanza. Rev. Psicopatol. Psicol. Clín. 2019, 24, 29-37. [CrossRef] 
13. Simbula, S.; Mazzetti, M.; Guglielmi, D. Conflitto lavoro/famiglia, burnout e work engagement negli insegnanti: Il ruolo moderatore delle risorse lavorative e personali. Av. Psicol. Latinoam. 2011, 29, 302-316.

14. Mousavy, S.; Thomas, N.S.; Mukundan, J.; Nimehchisalem, V. Burnout among Low and High Experienced Teachers. Int. J. Appl. Linguist. Engl. Lit. 2012, 1, 24-29. [CrossRef]

15. Mukundan, J.; Zare, P.; Zarifi, A.; Manaf, U.K.; Sahamid, H. Language Teacher Burnout and School Type. Engl. Lang. Teach. 2015, 8, 26-32. [CrossRef]

16. Luk, A.L.; Chan, B.P.; Cheong, S.W.; Ko, S. An Exploration of the Burnout Situation on Teachers in Two Schools in Macau. Soc. Indic. Res. 2010, 95, 489-502. [CrossRef]

17. Lou, Y.; Chen, L. A Study of the English Teachers' Burnout in a Local Comprehensive University in China. Creat. Educ. 2016, 7, 646-654. [CrossRef]

18. Li, S. A Case Study of the English Teachers' Burnout in a Medical University in China. Chin. J. Appl. Linguist. 2015, 38, 234-245. [CrossRef]

19. Ancona, M.; Mendelson, T. Feasibility and preliminary outcomes of a yoga and mindfulness intervention for school teachers. Adv. Sch. Ment. Health Promot. 2014, 7, 156-170. [CrossRef]

20. Ochentel, O.; Humphrey, C.; Pfeifer, K. Efficacy of Exercise Therapy in Persons with Burnout. A Systematic Review and Meta-Analysis. J. Sport. Sci. Med. 2018, 31, 248-255.

21. Domingues, R.B. Modern postural yoga as a mental health promoting tool: A systematic review. Complement. Ther. Clin. Pract. 2018, 31, 248-255. [CrossRef] [PubMed]

22. Silva, N.R.; Bolsoni-Silva, A.T.; Loureiro, S.R. Burnout syndrome and depression in elementary school teachers: A correlational study. Rev. Bras. Educ. 2018, 23, e230048.

23. Salmon, P. Effects of physical exercise on anxiety, depression and sensitivity to stress-A unifying theory. Clin. Psychol. Rev. 2001, 21, 33-61. [CrossRef]

24. Forcier, K.; Stroud, L.R.; Papandonatos, G.D.; Hitsmann, B.; Reiches, M.; Krishnamoorthy, J.; Niaura, R. Links between physical fitness and cardiovascular reactivity and recovery to psychological stressors: A meta-analysis. Health Psychol. 2006, 25, 723-739. [CrossRef] [PubMed]

25. Das, S. Global Mental Health, Peace and Sustainability: Does Yoga Show the Way? J. Depress. Anxiety 2017, 7, 1-3. [CrossRef]

26. Woodyard, C. Exploring the therapeutic effects of yoga and its ability to increase quality of life. Int. J. Yoga 2011, 4, 49-54. [CrossRef] [PubMed]

27. De Vries, J.D.; van Hooff, M.L.; Guerts, S.A.E.; Kompier, M.A.J. Exercise to reduce work-related fatigue among employees. A randomized controlled trial. Scand. J. Work Environ. Health 2017, 43, 337-349. [CrossRef]

28. Jain, R. Yoga and healthy lifestyle: The most desired products in today's stressful environment. South Asian J. Mark. Manag. Res. 2017, 7, 35-41. [CrossRef]

29. Weisner, M.L. Does Yoga Increase Sustainability? Enhanced Sensory Awareness and Environmental Behavior in South Florida. Worldviews 2020, 24, 58-80. [CrossRef]

30. Strauss, S.; Mandelbaum, L. Consuming Yoga, Conserving the Environment: Transcultural Discourses on Sustainable Living. In Yoga Traveling_Bodily Practice in Transcultural Perspective; Hauser, B., Ed.; Springer: Heidelberg, Germany, 2013.

31. Maltseva, N.V. Temperament properties as a predisposition factor to the burnout syndrome occurrence in the process of teacher's professional formation. Int. J. Psychosoc. Rehabil. 2020, 24, 3034-3046. [CrossRef]

32. Maji, S. A study of burnout syndrome of physical education teacher in purulia district. Int. J. Approx. Reason. 2019, 7, 163-168. [CrossRef]

33. McLean, D.; Eklund, K.; Kilgus, S.P.; Burns, M.K. Influence of teacher burnout and self-efficacy on teacher-related variance in social-emotional and behavioral screening scores. Sch. Psychol. 2019, 34, 503-511. [CrossRef] [PubMed]

34. Bulatevych, N. Teacher's burnout syndrome: The phenomenology of the process. Pol. J. Public Health 2017, 127, 62-66. [CrossRef]

35. Smetáčková, I.; Viktorova, I.; Martanova, V.P.; Páchová, A.; Francová, V.; Štěch, S. Teachers Between Job Satisfaction and Burnout Syndrome: What Makes Difference in Czech Elementary Schools. Front. Psychol. 2019, 10, 2287. [CrossRef]

36. Sane, M.A.; Devin, H.F.; Jafari, R.; Zohoorian, Z. Relationship Between Physical Activity and It's Components with Burnout in Academic Members of Daregaz Universities. Procedia Soc. Behav. Sci. 2012, 46, 4291-4294. [CrossRef]

37. Carraro, A.; Gobbi, E.; Moè, A. More gyms or more psychological support? Preventing burnout and supporting job satisfaction in physical education teachers. Sport Sci. Health 2016, 13, 55-62. [CrossRef]

38. Gura, S.T. Yoga for stress reduction and injury prevention at work. Work 2002, 19, 3-7.

39. Devi, S. Effectiveness of Yoga in Stress Management at Workplace: A Systematic Review. J. Emerg. Technol. Innov. Res. 2020, 7 , 546-555.

40. Seshachalam, A. Healthy Way to Handle Work Place Stress through Yoga, Meditation and Soothing Humor. IOSR J. Bus. Manag. 2016, 18, 18-25. [CrossRef]

41. Vyas-Doorgapersad, S.; Surujlal, J. Gender-based yoga for conflict resolution. Int. J. Bus. Manag. 2016, 8, $169-185$.

42. Yogitha, B.; Ebnezar, J. Can Yoga be an Effective Tool in Managing Psychological Stress. Am. J. Ethnomed. $2014,1,1-7$.

43. De Bruin, E.I.; Formsma, A.R.; Frijstein, G.; Bögels, S.M. Mindful2Work: Effects of Combined Physical Exercise, Yoga, and mindfulness Meditations for Stress Relieve in Employees. A Proof of Concept Study. Mindfulness 2017, 8, 204-217. [CrossRef] 
44. Smith, B.H.; Esat, G.; Kanojia, A. School-based yoga for managing stress and anxiety. In Applying Psychology in the Schools. Promoting mind-Body Health in Schools: Interventions for Mental Health Professionals; Maykel, C., Bray, M.A., Eds.; American Psychological Association: Washington, DC, USA, 2020; pp. 201-216. [CrossRef]

45. Hepburn, S.J.; McMahon, M. Pranayama Meditation (Yoga Breathing) for Stress Relief: Is It Beneficial for Teachers? Aust. J. Teach. Educ. 2017, 42, 142-159. [CrossRef]

46. Maslach, C.; Jackson, S.E.; Leiter, M.P. Maslach Burnout Inventory. In Evaluating Stress: A Book of Resources, 3rd ed.; Scarecrow Education: Lanham, MD, USA, 1997; pp. 191-218.

47. Hawrot, A.; Koniewski, M. Factor Structure of the Maslach Burnout Inventory-Educators Survey in a Polish-Speaking Sample. J. Career Assess. 2017, 26, 515-530. [CrossRef]

48. Sirigatti, S.; Stefanile, C. Adattamento Italiano del MBI-Maslach Burnout Inventory; Organizzazioni Speciali: Firenze, Italy, 1993.

49. Tanay, G.; Bernstein, A. State mindfulness Scale (SMS): Development and initial validation. Psychol. Assess. 2013, 25, 1286-1299. [CrossRef] [PubMed]

50. Hanson, J. Relax and Renew: Restful Yoga for Stressful Times; Rodmell Press: Berkeley, CA, USA, 2011.

51. La Torre, G.; Raffone, A.; Peruzzo, M.; Calabrese, L.; Cocchiara, R.A.; D’Egidio, V.; Leggieri, P.F.; Dorelli, B.; Zaffina, S.; Mannocci, A. Yoga and mindfulness as a Tool for Influencing Affectivity, Anxiety, Mental Health, and Stress among Healthcare Workers: Results of a Single-Arm Clinical Trial. J. Clin. Med. 2020, 9, 1037. [CrossRef]

52. Cohen, J. A Power Primer. Psychol. Bull. 1992, 112, 155-159. [CrossRef]

53. Li, A.W.; Goldsmith, C.A.W. The effects of yoga on anxiety and stress. Altern. Med. Rev. 2012, 17, 21-35.

54. Mothes, H.; Klaperski, S.; Seelig, H.; Schmidt, S.; Fuchs, R. Regular aerobic exercise increases dispositional mindfulness in men: A randomized controlled trial. Ment. Health Phys. Act. 2014, 7, 111-119. [CrossRef]

55. Alexander, G.K.; Rollins, K.; Walker, D.; Wong, L.; Pennings, J. Yoga for Self-Care and Burnout Prevention Among Nurses. Workplace Health Saf. 2015, 63, 462-470. [CrossRef] [PubMed]

56. Kravits, K.; McAllister-Black, R.; Grant, M.; Kirk, C. Self-care strategies for nurses: A psycho-educational intervention for stress reduction and the prevention of burnout. Appl. Nurs. Res. 2010, 23, 130-138. [CrossRef]

57. Raingruber, B.; Robinson, C. The effectiveness of Tai Chi, yoga, meditation, and Reiki healing sessions in promoting health and enhancing problem solving abilities of registered nurses. Issues Ment. Health Nurs. 2007, 28, 1141-1155. [CrossRef]

58. Liang, H.; Kao, Y.; Lin, C. Moderating Effect of Regulatory Focus on Burnout and Exercise Behavior. Percept. Mot. Ski. 2013, 117, 696-708. [CrossRef] [PubMed]

59. Dyrbye, L.; Satele, D.; Shanafelt, T. Healthy Exercise Habits Are Associated with Lower Risk of Burnout and Higher Quality of Life Among U.S. Medical Students. Acad. Med. 2017, 92, 1006-1011. [CrossRef]

60. Dujmić, Z.; Machielse, E.; Treur, J. A Temporal-Causal Modeling Approach to the Dynamics of a Burnout and the Role of Physical Exercise. In Biologically Inspired Cognitive Architectures 2018, Book Series Advances in Intelligent Systems and Computing volume 848, Proceedings of the Ninth Annual Meeting of the BICA Society, Prague, Czech Republic, 22-24 August 2018; Springer: Cham, Switzerland, 2018; pp. 88-100. [CrossRef]

61. Chu, I.H.; Lin, Y.J.; Wu, W.L.; Chang, Y.K.; Lin, I.M. Effects of Yoga on Heart Rate Variability and Mood in Women: A Randomized Controlled Trial. J. Altern. Complement. Med. 2015, 21, 789-795. [CrossRef] [PubMed]

62. Rosales-Ricardo, Y.; Montoro-Bombú, R.; Ferreira, J.P. The most effective physical exercise to reduce burnout syndrome in university students. J. Hum. Sport Exerc. 2020, 15, 518-530.

63. Fischetti, F.; Latino, F.; Cataldi, S.; Greco, G. Gender differences in body image dissatisfaction: The role of physical education and sport. J. Hum. Sport Exerc. 2020, 15, 241-250. [CrossRef]

64. Latino, F.; Greco, G.; Fischetti, F.; Cataldi, S. Multilateral training improves body image perception in female adolescents. J. Hum. Sport Exerc. 2019, 14, S927-S936.

65. Deshpande, R.C. A healthy way to handle work place stress through Yoga, Meditation and Soothing Humor. Int. J. Environ. Sci. 2012, 2, 976-4402. [CrossRef]

66. Michalsen, A.; Grossman, P.; Acil, A.; Langhorst, J.; Ludtke, R.; Esch, T.; Stefano, G.B.; Dobos, G.J. Rapid stress reduction and anxiolysis among distressed women as a consequence of a three-month intensive yoga programme. Med. Sci. Monit. 2005, 11, 555-561.

67. Reibel, D.K.; Greeson, J.M.; Brainard, G.C.; Rosenzweig, S. Mindfulness-based stress reduction and health-related quality of life in a heterogeneous patient population. Gen. Hosp. Psychiatry 2001, 23, 183-192. [CrossRef]

68. Cocchiara, R.A.; Peruzzo, M.; Mannocci, A.; Ottolenghi, L.; Villari, P.; Polimeni, A.; Guerra, F.; La Torre, G. The Use of Yoga to Manage Stress and Burnout in Healthcare Workers: A Systematic Review. J. Clin. Med. 2019, 8, 284. [CrossRef] [PubMed]

69. Zou, L.; Sasaki, J.E.; Wei, G.-X.; Huang, T.; Yeung, A.S.; Neto, O.B.; Chen, K.W.; Hui, S.C. Effects of mind-Body Exercises (Tai Chi/Yoga) on Heart Rate Variability Parameters and Perceived Stress: A Systematic Review with Meta-Analysis of Randomized Controlled Trials. J. Clin. Med. 2018, 7, 404. [CrossRef] 